\title{
From paper to practice - academics and practitioners working together in enhancing the use of occupational therapy conceptual models***
}

\author{
Mia Elsabie Vermaak, B OT (UFS) M OT (UFS) \\ Lecturer, Department of Occupational Therapy, School of Allied Health Sciences, Faculty of Health Sciences, University of the \\ Freestate
}

\section{Mariette Nel, M Med Sc (Biostatistics)}

Lecturer, Department of Biostatistics, School of Medicine, Faculty of Health Sciences, University of the Freestate

Introduction: Occupational therapy students are exposed to occupational therapy conceptual models in lectures, and are expected to practice application of these models during clinical fieldwork placements. During fieldwork, they are exposed to practitioners' approaches to the use of occupational therapy conceptual models, and are often confronted with a gap between theory and practice. The objective of this study was to investigate the use of conceptual models by occupational therapy practitioners in the Free State, South Africa, to inform collaborative efforts in the process of reinforcing the link between theory and practice, by enhancing the use of occupational therapy conceptual models.

Methods: A cross sectional study was done in two phases: by means of a questionnaire survey, with practitioners responsible for fieldwork supervision of students; and a workshop survey completed by practitioners attending a workshop on occupational therapy models.

Results: Results in the first phase describe the perceptions of 22 supervising practitioners around occupational therapy conceptual models; and their own and students' application thereof in practice. These results were used as the basis to design a workshop on the application of occupational therapy conceptual models. In the second phase, workshop survey questionnaires completed by 20 participants, indicated that they perceived the workshop as enabling with regard to applying new occupational therapy conceptual models with more confidence and competence, and that they felt more confident to supervise students in applying occupational therapy conceptual models during fieldwork.

Conclusion: This study and its resulting workshop show how collaboration between practitioners and academics can improve the link between theory and practice, benefiting practitioners' professional identity and ultimately impacting on undergraduate training.

Key words: Occupational therapy; occupational therapy conceptual models; occupational therapy practitioners supervising students; theory practice link; fieldwork education

\section{INTRODUCTION}

Occupation-based practice is gaining momentum in the profession of occupational therapy $1,2,3,4,5$. This is happening despite the pervasive presence of the biomedical model in most health care settings where South African occupational therapists are employed ${ }^{6}$. Occupation-based practice is in its essence holistic, aiming for improved occupational performance ${ }^{7}$; instead of the impairmentfocused biomedical approach to practice. With occupation-based practice and biomedical practice viewing health in different ways, tension often develops between theory and practice $^{8}$, underlying the so-called "academic-practice gap"| or theory-practice gap. Occupation-based practice is supported by theory on occupation from occupational science ${ }^{9,10}$, and specifically occupational therapy conceptual models ${ }^{10}$ (henceforth referred to as 'models'). These models provide explanations for the interaction of the person with his environment through occupations; providing practitioners with a framework for decision-making around occupation based intervention ${ }^{10,11,12,13}$.

The application of models in the occupational therapy process requires of and allows practitioners to make use of theory in their decision making. Model use also enhances occupation-based practice, by encouraging practitioners to choose occupation-based outcomes ${ }^{9}$ and tools of outcome measurement ${ }^{9}$. Explaining practice and the occupational therapy process, which often proves to be a complex and even tedious process, is simplified in that models provide practitioners with a language to do so ${ }^{14,15}$. It further holds

***A Article commemorating the UFS Anniversary a variety of benefits to practitioners (and ultimately clients too), ranging from increased professional resilience and career longevity $^{16}$, to clarifying professional identity ${ }^{9,16}$. Ultimately, the profession benefits from the use of models in that it guides us to offer an occupational therapy process that boldly reflects our profession's 'unique contribution' through occupation-based practice?.

These benefits notwithstanding, a number of factors play a role in practitioners' choice to use models or not, their choice of models and their proficiency in applying these models ${ }^{17,18}$.

Undergraduate training impacts on practitioners' confidence in their own use of models, which is problematic in view of limited literature about instruction of occupational therapy students on the use of models in practice ${ }^{17}$. Once in practice, the unavailability of role models and the pervasiveness of the medical model in occupational therapy practice, or at least some occupational therapy practice settings, hinder practitioners to apply occupation-based theory ${ }^{6,17}$. On top of this, there are limited resources for continued training in model application in practice ${ }^{17}$. Whilst Owen ${ }^{6}$ found in her study on South African practitioners that their use of models increased with years of practice; results from other countries indicate that the use of models declines with increased years of practice ${ }^{19}$. An encouraging finding, supported by Elliott, Velde and Wittman ${ }^{20}$ and Wong and Fisher ${ }^{21}$, is that although practitioners tend to admit to limited model use, they generally realise its value.

With universities and practitioners placing different premiums on theory and model use ${ }^{16,22}$, the theory-practice gap is perhaps most intensely experienced by undergraduate students in clinical fieldwork practice. In this process of "learning to think like a therapist"23:46, they are pressed between the academic expectations of 
applying a variety of models in practice, and practitioner supervisors - who may or may not be explicitly using models to support practice $^{24}$. A student participant in a study by Towns and Ashby ${ }^{16}$ might have captured this dissonance by saying "No disrespect to the teaching staff here but the teaching of theory is very idealistic...it is not practical" "6:347. Their study pointed out that students' fieldwork had a definite effect on their integration of theory and practice.

If one assumes practitioners will rather use models they were exposed to during undergraduate training, a way of slowly turning the tide toward increased model use and occupation-based practice, might be to accentuate theory-practice integration in current undergraduate students by increased training in model use. Similarly, the work of Kielhofner ${ }^{\prime}$ and Leclair et $\mathrm{al}^{18}$ on the theory-practice gap, inspired the collaborative process described in this article, where occupational therapists supervising students identified the need for training on model use and subsequently attended a workshop on model use. Our aim was therefore to demonstrate the process of collaboration between academics and practitioners, in order to advance the integration and model use of students.

\section{THE CONTEXT OF THIS STUDY}

Occupational Therapy students (hereafter referred to as students), at the University of the Free State (UFS), have over the last decade, been exposed to a variety of models in class. These models include the Model of Human Occupation (MOHO $)^{25}$, the Kawa River Model" ", the Canadian Model of Occupational Performance and Engagement (CMOP-E) $)^{13}$, the Jeanne Pretorius Activity Model (UFS model) ${ }^{26}$, the Person Environment Occupation Performance (PEOP) model ${ }^{12}$ and the Vona Du Toit Model of Creative Ability (VdT MOCA $)^{27}$. No prescriptions on which model to use in different areas of fieldwork are given during lectures. In reality, however, students were until as recently as 2012 mostly using the UFS model to assist in assessment, clinical reasoning and case presentations (personal communication) ${ }^{28}$. Students have therefore not had much opportunity to experiment with applying other models in practice. Over the past 3 to 4 years, students have been increasingly encouraged by both academics and practitioners involved in student supervision to use a more eclectic approach, allowing them to choose a model they deemed most appropriate for use in specific cases, groups or populations. At the same time, practitioners reported increasing uncertainty regarding the guidance of students in the use of models, and requested training from the Department of Occupational Therapy, UFS.

With limited information available to describe the use of models by South African practitioners, this study aims to illustrate how academics and practitioners may work together to reinforce the link between theory and practice. The research was planned and conducted by the lecturer responsible for the majority of undergraduate lectures on models at the Department of Occupational Therapy, UFS; and was performed prior to a workshop presented to practitioners in June 20I5. Hence, results from the survey informed the planning of the workshop content, with results from the workshop survey reflecting participants' experience of the workshop.

Students are expected to integrate theory and practice during fieldwork under the supervision of practitioners. In class over recent years, UFS students have been exposed to more models than most practitioners report having experience in using, and practitioners requested further training in the application of occupational therapy conceptual models in the occupational therapy process. The rationale for this study was thus to advance students' integration of theory and practice, by promoting model use amongst local practitioners who are involved in the supervision of students.

\section{METHODOLOGY}

The objective of the research was to investigate the application of occupational therapy conceptual models by practitioners involved in the supervision of third and fourth year students from the UFS, as well as to illustrate how academics and practitioners can work together to reinforce the link between theory and practice. A crosssectional study with convenience sampling was conducted, and all practitioners $(\mathrm{N}=44)$ involved in the supervision of UFS students (in their third and fourth year of study) on fieldwork placement were invited to participate and constituted the population. Practitioners were included based on the following criteria: reported current registration with the HPCSA, at least a diploma or degree in Occupational Therapy, and recent or current involvement (20I0-20I5) in student supervision.

A self-administered questionnaire was designed by the researchers, with multiple choice and open-ended questions. The questionnaire enquired about practitioners' previous exposure to models, their preferred models in own practice, as well as which models they prefer students to use in fieldwork. Their opinions on the value of model use were also explored. The questionnaire was piloted with three occupational therapy lecturers and minor changes were made regarding the technical layout of the questionnaire. The final questionnaire was distributed to practitioners by the first author by means of an email. Participants returned completed questionnaires via email to a colleague in an administrative position and not to the researchers, to protect participants' identities. The cut-off time for participation was prior to the first session of the workshop on model use in June 20I5, to prevent contamination of results by new knowledge gained during the workshop. Twenty-two $(n=22)$ questionnaires were returned, resulting in a response rate of $50 \%$.

The workshop, titled "Occupational Therapy Practice models: Theory and Application", was presented in eight sessions over two days in June 2015, by four lecturers (including the first author) from the Department of Occupational Therapy, UFS. The workshop was open for attendance by any occupational therapist, but was offered free of charge to practitioners involved in the supervision of UFS occupational therapy students doing fieldwork.

Immediately following the workshop, a self-administered questionnaire, enquiring about participants' experience of the workshop and their confidence and competence in model use, was distributed amongst all participants. The questionnaire with Likert scales and two open-ended questions, was designed by the researchers, in a style similar to standard workshop evaluation tools used by the Department of Occupational therapy. It contained three questions identical to those asked in the survey questionnaire used in the first phase, based on quotes taken from an article by Towns and Ashby $^{16}$. The workshop survey questionnaire was piloted with the three occupational therapy lecturers that presented the workshop, and no changes were indicated or made. All practitioners attending the workshop ( $N=25$, which excludes presenters), were asked to complete the survey questionnaires immediately after the last workshop session and return them to the registration table. No information allowing identification of participants was included in the questionnaire. Twenty questionnaires were completed and collected immediately after the final workshop session, resulting in a response rate of $80 \%(n=20)$.

\section{DATA ANALYSIS}

Descriptive statistics, namely frequencies and percentages for categorical data and medians and percentiles for continuous data were calculated. For the first part of the study (questionnaire survey) the number of models used by participants with graduate and post-graduate qualifications as well as for those who had obtained the last degree less than and more than 5 years prior to the workshop, were compared using a $95 \%$ confidence interval for the median differences.

\section{ETHICAL CONSIDERATIONS}

The Ethics Committees of both the Department of Health, Free State; and the Faculty of Health Sciences, UFS; approved the study prior to being conducted. All questionnaires were accompanied by an information document explaining the purpose and process of the 
study, and participants were informed that completion of the questionnaire indicated consent. Participants' identities were protected by requesting them to fax or email the completed questionnaires to an administrator, who printed questionnaires and provided it to the researchers without making any identities known. However, some demographic information on the questionnaires (such as age, work setting and postgraduate qualifications) could lead to identification of participants and all information was therefore handled confidentially. Workshop survey questionnaires were completed anonymously and handed to the presenters of the workshop.

\section{RESULTS}

\section{Survey questionnaire results: Current model use and practitioners' perceptions of model use}

The 22 practitioners who participated in the survey ranged in age from 25 to 56 years (Median: 33). Participants qualified between 1983 and 2012, with a median of 2006, and the median for the years since their last qualification is 5 , with the years ranging from 0 to 23 years. This relates to around 8 years of practice by the time of participation in the study (assuming no breaks were taken in working as a practitioner). Seventeen (I7) of the participants reported having obtained postgraduate qualifications, including a $\mathrm{PhD}$ in higher education ( $\mathrm{I}$ ) and master's degrees in occupational therapy (8) and early childhood intervention (I). Participants also reported qualifications in sensory integration (4) and neuro developmental therapy (3). All undergraduate qualifications $(n=22)$ and all but one $(n=9)$ postgraduate degrees, were obtained from the UFS.

The majority of practitioners were employed in the public sector $(72.7 \% ; n=16)$, with $18.2 \%(n=4)$ reporting private practice as their work setting and $9.1 \%(n=2)$ were working in academia fulltime. As can be seen in Table I, a wide variety of practices and patient populations are represented, including mental health practice (54.5\%; I2) and physical rehabilitation (45.5\%; 10$)$, but with limited community based intervention (18.2\%; 4).

Table I: Populations served by the sample of participating OT's $(\mathrm{n}=22)$ *

\begin{tabular}{|l|c|}
\hline & Percentage (frequency) \\
\hline Individual clients & $68.2 \%(15)$ \\
\hline Group intervention & $72.7 \%(16)$ \\
\hline Community based intervention & $18.2 \%(4)$ \\
\hline Children & $63.6 \%(14)$ \\
\hline Adolescents & $54.6 \%(12)$ \\
\hline Adults & $54.6 \%(12)$ \\
\hline Elderly clients & $36.4 \%(8)$ \\
\hline Mental health practice & $54.5 \%(12)$ \\
\hline Physical rehabilitation & $45.5 \%(10)$ \\
\hline *Therapists may have marked more than one practice area \\
\hline
\end{tabular}

Most practitioners $(77.3 \%)$ indicated that they were currently applying models and that they have done so in the past, with $22.7 \%$ responding that they were not using models in their daily practice. Practitioners with graduate qualifications reported using a median of 4 models (range 2 - 6), and practitioners with postgraduate qualifications reported using a median of 4 models (range 2 - 7). The number of models used by practitioners with graduate qualifications did not differ significantly from practitioners with post-graduate qualifications.

Two open-ended questions invited participants to describe their confidence and competence in model use (Table II). They described their confidence in applying models on levels varying from poor $(23.8 \%)$ to good $(33.3 \%)$. Descriptors of their own competence in model use included various levels, with the majority $(68.2 \%)$ indicating 'moderate' competence in model use.
Table II: Confidence and competence in model use: answers to open-ended questions $(n=22)$

\begin{tabular}{|l|c|}
\hline $\begin{array}{l}\text { Confidence: (“How would you describe } \\
\text { your confidence in applying models in } \\
\text { practice?") }\end{array}$ & $\begin{array}{l}\text { Percentage } \\
\text { (Frequency) }\end{array}$ \\
\hline Good & $33.3 \%(7)$ \\
\hline Moderate & $38.1 \%(8)$ \\
\hline Poor & $23.8 \%(5)$ \\
\hline Not really using models & $4.8 \%(I)$ \\
\hline $\begin{array}{l}\text { Competence: ("How would you describe } \\
\text { practice?") }\end{array}$ & $\begin{array}{c}\text { Percentage } \\
\text { (Frequency) }\end{array}$ \\
\hline Moderate & $68.2 \%(I 5)$ \\
\hline Very poor & $4.6 \%(I)$ \\
\hline Poor \& learning from students & $4.6 \%(I)$ \\
\hline Understand \& applying & $9.1 \%(2)$ \\
\hline Varying degrees - depending on the model & $13.6 \%(3)$ \\
\hline
\end{tabular}

Three statements based on an article by Towns \& Ashby ${ }^{16: 349}$ were included. Participants had to indicate their level of agreement with each statement. As shown in Table III, the majority of practitioners agreed with most statements.

Table III: Therapists level of agreement on three statements about theory use

\begin{tabular}{|l|c|c|c|}
\hline \multirow{2}{*}{} & \multicolumn{3}{|c|}{ Results: Survey (n=22) } \\
\cline { 2 - 4 } & AGREE & NEUTRAL & DISAGREE \\
\cline { 2 - 4 } & $\%$ (n) & $\%$ (n) & $\%$ (n) \\
\hline $\begin{array}{l}\text { "Theory guides } \\
\text { practice" 16:344-352 }\end{array}$ & $\begin{array}{c}73.3 \% \\
(16)\end{array}$ & $22.7 \%(5)$ & $4 \%(1)$ \\
\hline $\begin{array}{l}\text { "Being able to } \\
\text { communicate theory } \\
\text { underlying practice, } \\
\text { may enhance resilience } \\
\text { \& wellbeing" 16:344-352 }\end{array}$ & $\begin{array}{c}81.8 \% \\
(18)\end{array}$ & $9.1 \%(2)$ & $9.1 \%(2)$ \\
\hline $\begin{array}{l}\text { "Being able to } \\
\text { communicate theory } \\
\text { underlying practice, } \\
\text { may enhance career } \\
\text { longevity" 16:344-352 }\end{array}$ & $\begin{array}{c}86.4 \% \\
(19)\end{array}$ & $13.6 \%(3)$ & $0 \%(0)$ \\
\hline
\end{tabular}

Practitioners were asked to indicate the models preferred by students working under their supervision in fieldwork. Three favourites were identified namely: the VdT MOCA, UFS Activity model and the MOHO. When given the opportunity to indicate which models they would prefer students to use in clinical fieldwork, 9 practitioners indicated that they had no preference regarding model use by students (See Table IV on page 38 ). When analysing the number of models used in relation to years since last qualification, no statistically significant results were obtained. The median number of models used by practitioners graduating (both graduate or post-graduate) in the five years up to and including 2015 is 5 (range $2-7$ ); with the median number of models used by practitioners obtaining qualifications more than five years ago being 3.5 (range 2 - 5). There might be a tendency for practitioners having obtained a qualification less than 5 years ago to report using more models, although this was not statistically significant $(95 \%$ confidence interval for the median difference $[0 ; 3]$ ).

A final, open ended question invited participants to make final comments on 'the use of models in practice'. The range of comments included a variation of critique on models as well as reasons for not using it (Figure I on page 38). 
Table IV: Model use by students - as reported and preferred by supervising therapists $(n=22)$

\begin{tabular}{|c|c|c|c|c|c|}
\hline & & $\begin{array}{l}\text { Currently reported } \\
\text { by therapists as being } \\
\text { used by students }\end{array}$ & $\begin{array}{l}\text { Preferred by } \\
\text { therapists for } \\
\text { student use }\end{array}$ & $\begin{array}{c}\text { Models received training } \\
\text { in, on undergraduate or } \\
\text { post-graduate level or } \\
\text { elsewhere }\end{array}$ & $\begin{array}{l}\text { Models requested } \\
\text { for inclusion in the } \\
\text { workshop program }\end{array}$ \\
\hline & & $\%(n)$ & $\%(n)$ & $\%(n)$ & $\%(n)$ \\
\hline $\begin{array}{l}\text { Models offered as } \\
\text { options / answers in }\end{array}$ & $\begin{array}{l}\text { UFS Activity } \\
\text { model }\end{array}$ & $59.1 \%(13)$ & $22.7 \%(6)$ & $86.4 \%(19)$ & $0.0 \%(0)$ \\
\hline & Kawa & $31.2 \%(7)$ & $18.2 \%(4)$ & $59.1 \%(13)$ & $7.1 \%(1)$ \\
\hline & $\mathrm{MOHO}$ & $59.1 \%(13)$ & $27.3 \%(6)$ & $68.2 \%(15)$ & $21.4 \%(3)$ \\
\hline & CMOP-E & $31.2 \%(7)$ & $36.4 \%(8)$ & $63.6 \%(14)$ & $42.9 \%(6)$ \\
\hline & VdT MOCA & $63.6 \%(14)$ & $27.3 \%(6)$ & $90.2 \%(20)$ & $0 \%(0)$ \\
\hline & PEOP & $13.6 \%(3)$ & $9.1 \%(2)$ & $9.1 \%(2)$ & $2 \%(14.3)$ \\
\hline Models mentioned by & Wall model & $9.1 \%(2)$ & $0 \%(0)$ & $9.1 \%(2)$ & $0 \%(0)$ \\
\hline respondents in 'other' & $\begin{array}{l}\text { Adaptation } \\
\text { through } \\
\text { occupation }\end{array}$ & $0 \%(0)$ & $4.6 \%(I)$ & $4.6 \%(I)$ & $1 \%(7.14)$ \\
\hline & PEO & $0 \%(0)$ & $0 \%(0)$ & $4.6 \%(I)$ & $0 \%(0)$ \\
\hline & $\begin{array}{c}\text { Clinical } \\
\text { Reasoning }\end{array}$ & $0 \%(0)$ & $0 \%(0)$ & $4.6 \%(I)$ & $0 \%(0)$ \\
\hline & No preference & regarding model use by stu & dents & & $40.2 \%(9)$ \\
\hline
\end{tabular}

- "Models are sometimes too technical".

- "Models are not really used by occupational therapists in practice".

- "I understand that students have to use models, but I don't really (use models)."

- "Models explain the person in a holistic and person-specific approach. I, however, do not apply it like this in my practice".

- "Using a model for the sake of using one without insight holds no purpose. However, using it insightfully grounds the profession".

- " "If all of us could understand models - magic!".

- "I think models are valuable in directing therapy. Undergraduate exposure (to models) is too limited and models are not often enough applied in practice".

- "It is difficult to link theory and practice with limited knowledge".

- ' 'It is good and 'lekker' (pleasing) to use models. I recommend model 'language' can be simplified to make it more accessible to people outside of occupational therapy".

- "Unknowingly using models in practice".

- "Everybody is understaffed and therefore not often willing or able to spend extra time or effort to study new models. However, once you've mastered a model it can be used without much effort".

- "Limited research is available on model use in South Africa, I am therefore very grateful for this study'.

- 'We need clarity on whether 'Creative ability' is a model or a theoretical frame of reference".

Figure I: Verbatim quotes from therapists about using models in practice

\section{Workshop survey questionnaire results: practitioners' perceptions and intention of mode- use after workshop attendance}

The workshop on model-use was attended by 20 practitioners (henceforth referred to as 'participants'), of whom the majority was employed in the public sector and involved in student supervision. Based on the results obtained from the first survey, the workshop contained an introductory theoretical session on the $\mathrm{MOHO}$, Kawa, PEOP and CMOP-E models. Each theoretical session of the workshop was followed by small group discussions where participants were challenged to apply a single case study on the freshly presented model.
At completion of the workshop on model-use (see Table $V$ ), all participants $(n=20)$ reported feeling more competent in applying the models in practice as well as in their ability to communicate the theory underlying the model.

Table V: Confidence and competence in following attendance of the workshop $(n=20)$

\begin{tabular}{|l|c|c|c|}
\hline & Agree & Neutral & Disagree \\
\cline { 2 - 4 } & $\%$ (n) & $\%(\mathbf{n})$ & $\%(\mathbf{n})$ \\
\hline $\begin{array}{l}\text { After this workshop I feel } \\
\text { more knowledgeable and } \\
\text { competent to apply models in } \\
\text { practice. }\end{array}$ & $\begin{array}{c}100 \% \\
(20)\end{array}$ & $0 \%(0)$ & $0 \%(0)$ \\
\hline $\begin{array}{l}\text { This workshop has improved } \\
\text { my ability to communicate } \\
\text { the underlying theory of } \\
\text { occupational therapy. }\end{array}$ & $\begin{array}{c}100 \% \\
(20)\end{array}$ & $0 \%(0)$ & $0 \%(0)$ \\
\hline $\begin{array}{l}\text { After this workshop I feel } \\
\text { more competent to } \\
\text { supervise students in the } \\
\text { application of these models } \\
\text { (n= I9) }\end{array}$ & $94.7 \%(18)$ & $5.3 \%(1)$ & $0 \%(0)$ \\
\hline $\begin{array}{l}\text { After this workshop I am } \\
\text { planning on applying models } \\
\text { I have not used before. }\end{array}$ & $90 \%(18)$ & $10 \%(2)$ & $0 \%(0)$ \\
\hline
\end{tabular}

Nearly all participants (90\%) indicated their intention to apply 'new models'. In a question about the supervision of students in model-use, following attendance of this workshop, 19 participants $(94.7 \%)$ agreed that they now felt more competent in offering supervision regarding the use of models.

Participants were given the opportunity to indicate their level of agreement (Table VI on page 39) with the same three statements from Towns \& Ashby ${ }^{16: 349}$ used in the first survey, and reported in Table III. When compared to the results from the first survey, a similar trend of agreement was noted, with one difference: fewer participants $(75 \%)$ felt that their career longevity would be enhanced by an increased ability to communicate the theory underlying practice; than practitioners in the first survey $(86.4 \%)$. 
Table VI: Workshop attendees opinions on three statements about theory use ${ }^{16: 344-352}(n=20)$

\begin{tabular}{|l|c|c|c|}
\hline & AGREE & NEUTRAL & DISAGREE \\
\cline { 2 - 4 } & $\%$ (n) & $\%(\mathbf{n})$ & $\%$ (n) \\
\hline $\begin{array}{l}\text { "Theory guides practice" } \\
\text { 16:344-352 }\end{array}$ & $\begin{array}{c}84.2 \% \\
(17)\end{array}$ & $10.5 \%(2)$ & $5.3 \%(I)$ \\
\hline $\begin{array}{l}\text { "Being able to } \\
\text { communicate theory } \\
\text { underlying practice, may } \\
\text { enhance resilience \& } \\
\text { wellbeing" 16:344-352 }\end{array}$ & $85 \%(I 7)$ & $5 \%(I)$ & $10 \%(2)$ \\
\hline $\begin{array}{l}\text { "Being able to } \\
\text { communicate theory } \\
\text { underlying practice, may } \\
\text { enhance career longevity" } \\
\text { 16:344-352 }\end{array}$ & $75 \%(15)$ & $20 \%(4)$ & $5 \%(I)$ \\
\hline
\end{tabular}

\section{Discussion \& implications}

The initial survey results reflect practitioners' perception of their own and students' use of models in practice and fieldwork. The workshop survey results reflect how the workshop positively influenced practitioners' perception of, and their confidence in model-use and the related supervision of students.

Demographic results from the survey indicate good representation of student fieldwork placement areas, with the public sector being much more represented than the private sector. The response rate of $50 \%$ is lower than ideal and yet, both mental and physical health practices, and all patient populations, were represented in a realistic reflection of the clinical fieldwork practice areas. Practitioners who are interested in model-use may have been more inclined to participate in this specific study. This is possibly reflected by results showing that the majority $(77.3 \%)$ of participants reported using models in daily practice; with a similar majority indicating their interest in attending the workshop on model-use in June 2015. This apparent interest in theory may also be reflected by the fact that a similar number of participants reported post-graduate qualifications. Kielhofner's' observation that experienced practitioners tend to rely on theory use even less than younger practitioners, could therefore not be statistically confirmed by our results. However, it seems a tendency for practitioners having graduated more recently to report using a greater number of models. This is in contrast with Owen's:45 finding that the 'number and variety of models used increased with the number of years that participants were qualified'.

The trend regarding practitioners' and students' choice of models was that students, according to participants, prefer the UFS Activity Model, MOHO and VdT MOCA; which are also the three models that the majority of participants pointed out as the ones they had been exposed to in their own undergraduate or further studies. The preference for these three models from their undergraduate training is no surprise, considering all participants completed their graduate studies at the UFS, where the VdT MOCA and the UFS Activity Model have been taught more extensively than any of the other models until recently ${ }^{28}$. It seems that participants feel more comfortable using the models they experienced as undergraduate students themselves, as is also reflected in other studies ${ }^{6,17}$. However, participants indicated a preference for the $\mathrm{MOHO}$ and $\mathrm{VdT}$ MOCA, with the CMOP-E taking the third place instead of the UFS Activity Model.

With Owen's ${ }^{6}$ study of 2014 being the only other similar South African study to compare our results to, it is noteworthy that her participants also favoured the MOHO and the VdT MOCA above other models, as portrayed in this study. The UFS Activity Model however, did not feature in her results at all. This may be explained by the fact that her sample included participants from other univer- sities where students are exposed to different theoretical models of practice, whereas our participants all completed their studies at the UFS, where the UFS Activity Model has been designed and taught exclusively by an alumni lecturer of the UFS.

Workshop participants' reported an increase of confidence in model use and student supervision, and their intention to apply new models, indicates needs-driven training as a first step of collaboration in strengthening the theory-practice link.

Following the workshop, fewer participants agreed that an increased ability to communicate theory would enhance career longevity when compared to the first survey. This could be discouraging, and contradicts studies such as that of Wimpenny ${ }^{29}$, who illustrated how theory-advancement processes strengthened practitioners' professional identities and enthusiasm about their work. This further indicates the need for ongoing collaboration to bridge the theory-practice gap.

Despite these promising results about participants' perception of the workshop, we agree that the integration of theory into daily practice "remains challenging"|18:182 and that transformation of practice by the integration of theory is rather more complicated 18,29 than presenting an once-off workshop.

However, even though this two-day workshop was limited in its capacity to transform practice by model-use, it opens up the dialogue between practitioners and academics about the use of models'; and using theory with intention ${ }^{18}$.

\section{CONCLUSION AND RECOMMENDATIONS}

This paper indicates how student fieldwork continues to turn the spotlight on the theory-practice gap, compelling academics and practitioners to bridge this gap through collaboration. The results of the first survey provided the first author with material to design a needs-driven workshop. The results from the workshop survey revealed the participants reported being more confident in modeluse and student supervision, and willing to use new models following the workshop.

The authors recommend follow-up workshops on model-use, focusing more specifically on using occupational therapy models in different fields of practice, for example community based practice, or paediatric occupational therapy. These workshops may be informed by follow-up surveys, monitoring the use of models by practitioners, as well as students.

Building on the apparent tendency for practitioners to continue with the use of models they were exposed to during undergraduate training, the researchers trust that the current generation of undergraduate students will carry with them an appreciation for theory and specifically occupational therapy conceptual models. At the same time, practitioners who are exposed to students' use of theory, may benefit from being continuously exposed to model-use and remain in contact with ongoing learning opportunities. If these learning opportunities are planned according to specific principles of theory advancement ${ }^{1,18,29}$; it is expected to lead to strengthened professional identities of practitioners, ultimately creating an environment where students can more efficiently negotiate the grey area between paper and practice.

\section{ACKNOWLEDGEMENTS}

Every occupational therapist who participated in the study, pilot study and/or workshop; and for your continued efforts in guiding students in the application of theory in practice.

Sanet Du Toit, Marieta Visser and Monique Strauss for assisting in the process of planning and executing this study and disseminating results via presentation and publication.

UFS - funding which allowed me to present this paper at the Asia Pacific Occupational Therapy Congress 2015 in Rotorua, New Zealand.

Dr Christel Troskie-de Bruin and Prof Gina Joubert for reviewing this article. 


\section{REFERENCES}

I. Kielhofner G. Scholarship and practice: bridging the divide. The American Journal of Occupational Therapy, 2005; 59(2): 23I-239. http://doi.org/I0.50I4/ajot.59.2.23I.

2. Polatajko HJ, Davis J, Cantin N, Dubouloz-Wilner CJ, \& Trentham B. Occupation-based practice: The essential elements. Chapter 8. In Enabling Occupation II: Advancing an occupational therapy vision for health, well-being and justice through occupation. Edited by Townsend EA, Polatajko, HJ. CAOT Publications ACE. 2007: 203-228.

3. Tomori K, Nagayama H, Ohno K, Nagatani R, Saito Y, Takahashi K, Higashi T. Comparison of occupation-based and impairment-based occupational therapy for subacute stroke: A randomized controlled feasibility study. Clinical Rehabilitation, 2014; 29(8): 752-62. http:// doi.org/10.1 I77/02692155।4555876.

4. Ashby SE, Ryan S, Gray M \& James C. Factors that influence the professional resilience of occupational therapists in mental health practice. Australian Occupational Therapy Journal, 2013; 60(2), II0I19. http://doi.org/10.1 II I/I440-1630.12012.

5. Colaianni DJ, Provident I, DiBartola LM. and Wheeler S. A phenomenology of occupation-based hand therapy. Australian Occupational Therapy Journal, 2015; 62: I77-186. doi: I0.1III/1440-1630.12192.

6. Owen A, Adams F, Franszen D. Factors influencing model use in occupational therapy. South African Journal of Occupational Therapy, 20I4; 44(I): 4I-47.

7. Che Daud AZ, Yau MK, Barnett F, Judd, J. Occupation based intervention in hand injury rehabilitation: experiences of occupational therapists in Malaysia. Scandinavian Journal of Occupational Therapy, 2016; 23(I): 57-66.

8. Wilding C, Whiteford G. Occupation and occupational therapy: Knowledge paradigms and everyday practice. Australian Occupational Therapy Journal, 2007; 54: 185-193. doi: 10.1 III/j. I4401630.2006.00621.

9. Joosten AV. Contemporary occupational therapy: Our occupational therapy models are essential to occupation centred practice. Australian Occupational Therapy Journal, 2015; 62(3) 219-222.

10. Lee SW, Taylor R, Kielhofner G, Fisher G. Theory use in practice: a national survey of therapists who use the Model of Human Occupation. The American Journal of Occupational Therapy, 2008; 62(I): 106-II7. http://doi.org/10.5014/ajot.62.1.106.

II. Iwama M. The Kawa Model - Culturally Relevant Occupational Therapy. $\left.\right|^{\text {st }}$ ed. United States of America: Churchill Livingstone Elsevier; 2006.

12. Christiansen $\mathrm{CH}$, Baum CM. Person-Environment-OccupationPerformance: An Occupation-Based Framework for Practice. In Occupational Therapy: Performance, Participation, Well-Being. Edited by Christiansen $\mathrm{CH}$, Baum CM, Bass-Haugen J. Thorofare: SLACK. 2005: 242-267.

13. Polatajko HJ, Townsend EA, Craik J. Specifying the domain of concern: occupation as core. Chapter I. In Enabling Occupation II: Advancing an occupational therapy vision for health, well-being and justice through occupation. Edited by Townsend EA, Polatajko, HJ. CAOT Publications ACE. 2007: 22-36.

14. Turpin M, Iwama MK. Using occupational therapy models in practice: A field guide. Toronto: Churchill Livingstone Elsevier, 20I I.

15. Ashby S, Chandler B. An exploratory study of the occupationfocused models included in occupational therapy professional education programmes. British Journal of Occupational Therapy, 2010: 616-624.

16. Towns $E$, Ashby $S$. The influence of practice educators on occupational therapy students' understanding of the practical applications of theoretical knowledge: A phenomenological study into student experiences of practice education. Australian Occupational Therapy Journal. 20I4; 5: 344-352.

17. Ikiugu MN, Smallfield S. Instructing occupational therapy students in use of theory to guide practice. Occupational Therapy in Health Care, 2015; 165-177.

18. Leclair LL, Ripat JD, Wener PF, Cooper, JE, Johnson LA, Davis ELO, Campbell-Rempel, MA. Advancing the use of theory in occupational therapy: A collaborative process / Promouvoir l'application de la theorie en ergotherapie : un processus de collaboration. Canadian Journal of Occupational Therapy, 2013; 80(3): I8I-193. http://doi. org/10.1177/0008417413495182.

19. O'Neal S, Dickerson AE, Holbert D. The use of theory by occupa- tional therapists working with adults with developmental disabilities. Occupational Therapy in Health Care, 2007; 2 I (4): 7I-85.

20. Elliott SJ, Velde BP, Wittman PP. The use of theory in everyday practice: An exploratory study. Occupational Therapy in Health Care. 2002; I6(I): 45-62.

2I. Wong SR, Fisher G. Comparing and using occupation-focused models. Occupational therapy in health care, 20I5: 29(3): 297-3I5.

22. Rodger S, Fitzgerald C, Davila W, Millar F, Allison H. What makes a quality occupational therapy practice placement? Students' and practice educators' perspectives. Australian Occupational Therapy Journal, 20I I; 58(3): 195-202.

23. Nelson DL, Chapman, LM. Occupational Analysis and Synthesis. Ergoterapeuten, 20I5; v3: 46-53.

24. Bonsaksen T, Celo C, Myraunet I, Granå KE, Ellingham B. Promoting academic-practice partnerships through students' practice placement. International Journal of Therapy And Rehabilitation, 2013; 20(I): 33-9.

25. Kielhofner G. A model of human occupation: Theory and application. Lippincott Williams \& Wilkins; 2002.

26. Pretorius J. A model of ontogenesis and the dynamics of occupational function and dysfunction. Chapter 2. In Occupational Therapy in psychiatry and mental health. $3^{\text {rd }}$ ed. Edited by Crouch RB, Alers VM. Maskew Miller Longman. 1997: 46-78.

27. Du Toit V. Patient volition and action in occupational therapy, $3^{\text {rd }}$ ed. Pretoria: Vona \& Marie du Toit Foundation, 2004.

28. Du Toit S. Lecturer in occupational therapy. $28^{\text {th }}$ January 2016.

29. Wimpenny K, Forsyth K, Jones C, Matheson L, Colley J. Implementing the Model of Human Occupation across a mental health occupational therapy service: communities of practice and a participatory change process. The British Journal of Occupational Therapy. 2010; 73(II): 507-I6.

Corresponding Author

Mia Vermaak

vermaakme@ufs.ac.za 